\title{
Ensino de pós-graduação em Saúde Coletiva: situação atual e desafios para o futuro
}

\section{Collective Health Graduate Program: present situation and challenges to the future}

\section{Estudios de posgrado en Salud Colectiva: situación actual y desafíos hacia el futuro}

Rita Barradas Barata, doutora em Medicina Preventiva pela Faculdade de Ciências Médicas da Santa Casa de São Paulo. Endereço: Rua Dr. Cesário Mota Jr., 61. CEP: 01221-020 - São Paulo, SP. Telefone (11) 3367-7776. E-mail: rita.barradasbarata@ gmail.com.

Ricardo Ventura Santos, doutor em Saúde Pública pela Escola Nacional de Saúde Pública (Fiocruz). Endereço: Rua Leopoldo Bulhões, 1480. CEP: 21031-210 - Rio de Janeiro, RJ. Telefone: (21) 2598-2542. E-mail:santos@ensp.fiocruz.br.

\section{Resumo}

O artigo trata dos desafios para a pós-graduação em Saúde Coletiva neste início de século XXI, considerando tanto os aspectos específicos desse tipo de formação quanto as transformações ocorridas no campo das práticas em saúde pública em função das transformações sociais e históricas. O principal objetivo é problematizar diferentes aspectos que podem balizar a formulação dos programas de pós-graduação. O texto está constituído por um breve histórico do desenvolvimento da pós-graduação na área, considerações sobre a situação atual dos programas credenciados, os desafios para o futuro da pós-graduação senso estrito, as repercussões do processo de globalização para os saberes e práticas da saúde pública, a nova saúde pública e os desafios para a formação acadêmica e profissional. 
Palavras-chave: Ensino de Pós-Graduação. Saúde Pública. Saúde Coletiva.

\section{Abstract}

The article discusses the challenges for graduate programs in Public Health at the beginning of the XXI century, considering the specific aspects of training such as the changes in the field of public health practices in terms of social and historical transformations. The main objective is to discuss different aspects that should inform the formulation of graduate programs. The text is composed of a brief history of the development of graduate studies in the area, considerations about the current status of accredited programs, challenges for the future of this area, the implications of globalization for the knowledge and practices of public health, and the new public health challenges for academic and professional training.

Keywords: Graduate Program. Public Health. Collective Health

\section{Resumen}

El estudio analiza los desafíos del posgrado en Salud Colectiva a principios del siglo XXI, teniendo en cuenta los aspectos específicos de este tipo de formación y los cambios ocurridos en el campo de las prácticas de salud pública a la luz de las transformaciones sociales y históricas. El principal objetivo fue la problematización de diferentes aspectos que pueden orientar la formulación de programas de posgrado. El texto se compone de una breve historia del desarrollo del posgrado en este área, consideraciones acerca de la situación actual de los programas acreditados, los retos para el futuro del posgrado stricto sensu, las implicaciones del proceso de globalización para los saberes y las prácticas de la salud pública, la nueva salud pública y los desafíos para la formación académica y profesional.

Palabras clave: Posgrado. Salud Pública. Salud Colectiva. 
Introdução

O campo da Saúde Coletiva constituiu-se no Brasil, enquanto campo teórico e de práticas, durante os anos 70 e desde então vem apresentando expressivo crescimento como campo de produção de conhecimentos, formação de pesquisadores, formação de profissionais e atuação na formulação, execução e avaliação política nacional de saúde.

A prática tradicional de Saúde Pública sofreu grandes transformações durante esse período sob a influência de processos sociais e políticos mais amplos, mas também como decorrência da configuração desse novo campo de conhecimentos da Saúde Coletiva.

Neste artigo, apresentamos um breve histórico do desenvolvimento da pós-graduação na área e o retrato atual dos programas. Em seguida, passamos a discutir um conjunto de desafios que a área como um todo tem a enfrentar para prosseguir em seu crescimento. Finalmente, discutimos uma série de desafios para cada curso em particular, no sentido de responder de maneira apropriada às transformações sociais e às novas demandas teóricas e práticas que se colocam para a prática em Saúde Coletiva.

\section{Breve histórico}

O ensino de pós-graduação estrito senso, no campo da Saúde Coletiva, teve início no País na década de 70. Até então, a formação em Saúde Pública ocorria apenas nos cursos de especialização ministrados pela Faculdade de Saúde Pública da Universidade de São Paulo e pela Escola Nacional de Saúde Pública da Fundação Oswaldo Cruz e nos programas de residência médica em Medicina Preventiva ou Social mantidos por alguns departamentos de escolas médicas (BARATA, 1997).

O primeiro curso de mestrado criado no País foi iniciado em 1970 na Faculdade de Saúde Pública em São Paulo. No ano seguinte, 
teve início o programa da Faculdade de Medicina de Ribeirão Preto e, em 1973, o da Faculdade de Medicina em São Paulo, todos da USP. O primeiro curso de doutorado foi instituído em Ribeirão Preto em 1971, seguindo-se os doutorados da Faculdade de Medicina e da Faculdade de Saúde Pública em 1973 e 1978, respectivamente, todos na Universidade de São Paulo (CAPES, 2010).

Ainda na década de 70, foram criados os mestrados da Universidade Federal da Bahia e do Instituto de Medicina Social da UERJ, ambos em 1974, além do mestrado da Escola Nacional de Saúde Pública em 1977. Assim, durante essa primeira década, existiam apenas seis cursos de mestrado e três cursos de doutorado em Saúde Pública no País, sendo que o programa da Faculdade de Medicina de São Paulo era oferecido em Medicina Preventiva e apenas para médicos. Além do número pequeno, os cursos estavam concentrados no eixo Rio-São Paulo, com exceção do mestrado da UFBA (Ibidem).

Na década seguinte, há acréscimo de apenas três cursos aos já existentes: a criação dos doutorados da UFBA e da ENSP e um novo mestrado no Instituto Fernandes Figueira na Fiocruz. Portanto, o número de programas continua insuficiente e a concentração espacial permanece idêntica à da década anterior, tendo havido apenas a extensão do doutorado para o Rio de Janeiro e Salvador (Ibidem).

Foi a partir da década de 90 que a área experimentou marcado crescimento dos cursos de mestrado e doutorado. Ao final do século XX, os programas haviam passado dos sete existentes em 1989 para 16 programas. Em termos de distribuição geográfica, aos programas existentes em São Paulo, Rio de Janeiro e Salvador vieram se juntar programas em Londrina (PR), Pelotas (RS), Florianópolis (SC), Recife (PE), Fortaleza (CE) e Belo Horizonte (MG). Nessa década, surgiram também os cursos no interior do estado de São Paulo, na Universidade de Campinas e na Universidade Estadual Paulista Júlio de Mesquita Filho(Unesp/Botucatu), e o programa da Universidade Federal do Rio de Janeiro. Dessa forma, a pós-graduação estrito senso chegou a todos os estados da região Sul, a três estados da região Sudeste e a três estados da região Nordeste (Ibidem). 
Nos últimos 10 anos, a expansão foi ainda mais acelerada, passando de 16 programas no final da década de 90 para os atuais 63 programas em 2010. Destaca-se, nesse período, a introdução do mestrado profissional como nova modalidade de formação (LEAL; FREITAS, 2006).

\section{Situação atual}

Atualmente, existem em funcionamento 63 programas e 84 cursos na área da Saúde Coletiva, credenciados pela Fundação Capes (Coordenação de Aperfeiçoamento de Pessoal de Nivel Superior). Desses, 39 são programas acadêmicos com mestrado, doutorado ou ambos os cursos; 24 são programas de mestrado profissional.

Os programas acadêmicos estão presentes em 16 das unidades da Federação, havendo pelo menos um programa em cada uma das regiões brasileiras (Tabela 1 ).

Tabela 1. Distribuição dos programas acadêmicos e profissionais de pós-graduação em Saúde Coletiva segundo regiões brasileiras, 2011

\begin{tabular}{|l|c|c|c|c|c|c|}
\hline \multirow{2}{*}{ Região } & \multicolumn{2}{|c|}{$\begin{array}{c}\text { Programas } \\
\text { acadêmicos }\end{array}$} & \multicolumn{2}{c|}{$\begin{array}{c}\text { Programas de mestrado } \\
\text { profissional }\end{array}$} & \multicolumn{2}{c|}{ Total } \\
\cline { 2 - 8 } & $\mathbf{N}^{\circ}$ & $\%$ & $\mathbf{N}^{\circ}$ & $\%$ & $\mathbf{N}^{\circ}$ & $\%$ \\
\hline Norte & 1 & 2.6 & 0 & 0.0 & 1 & 1.6 \\
\hline Nordeste & 11 & 28.2 & 4 & 16.7 & 15 & 23.8 \\
\hline Sudeste & 19 & 48.7 & 13 & 54.2 & 32 & 50.8 \\
\hline Sul & 6 & 15.4 & 5 & 20.8 & 11 & 17.5 \\
\hline Centro-Oeste & 2 & 5.1 & 2 & 8.3 & 4 & 6.3 \\
\hline Total & $\mathbf{3 9}$ & 100.0 & $\mathbf{2 4}$ & $\mathbf{1 0 0 . 0}$ & $\mathbf{6 3}$ & $\mathbf{1 0 0 . 0}$ \\
\hline
\end{tabular}

Fonte: Capes (http:/www.capes.gov.br).

Os dados mostram que há proporção significativa de programas profissionais na área de Saúde Coletiva, alcançando aproximadamente $38 \%$ do total de programas da área. Para a grande área da saúde, apenas $5 \%$ dos programas são de mestrados profissionais. A área da Saúde Coletiva é a que apresenta a maior proporção de programas 
nessa modalidade, seguida pela área de Odontologia. Chama a atenção ainda haver maior proporção de programas na região Nordeste do que na região Sul, sugerindo uma relativa desconcentração espacial dos cursos. Também nesse aspecto a área se destaca no interior da grande área da saúde, pois, para ela, somente $16 \%$ dos programas encontramse na região Nordeste. No entanto, há notória escassez de cursos tanto na região Norte quanto na região Centro-Oeste, acompanhando o perfil observado para a grande área da saúde como um todo.

A distribuição dos programas por unidade da Federação apresentada no Gráfico 1 mostra maior concentração no Rio de Janeiro, em São Paulo e no Rio Grande do Sul.

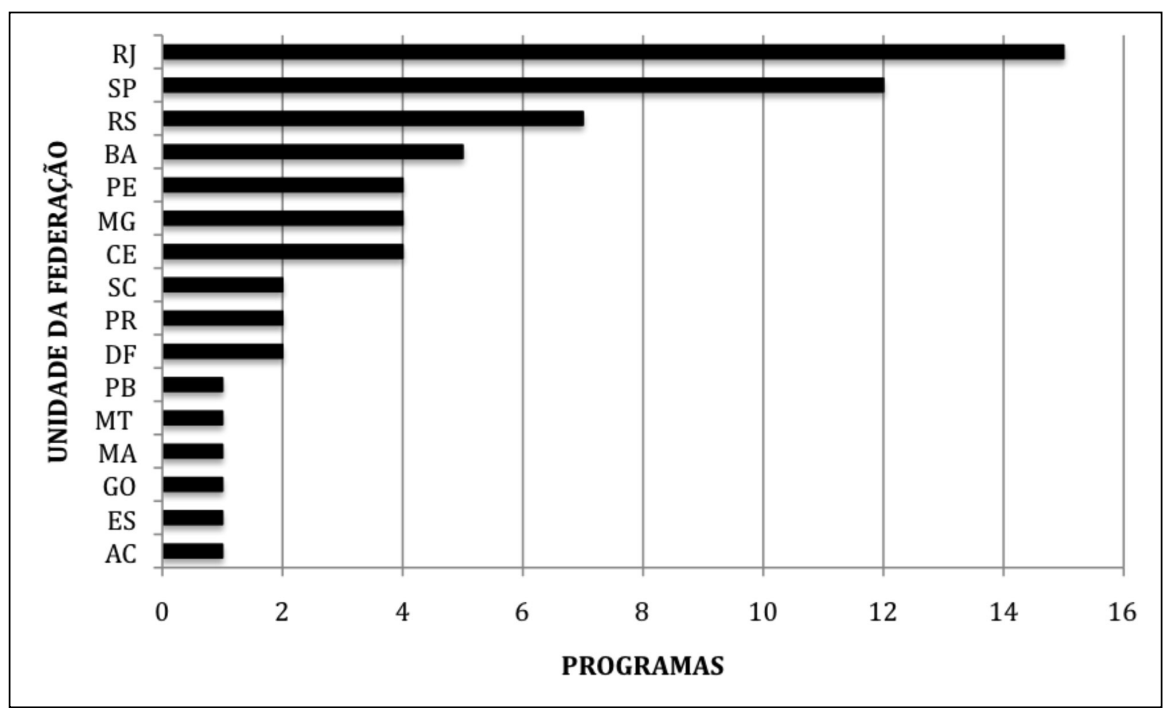

Fonte: Capes (http:/www.capes.gov.br).

\section{Gráfico 1. Programas de pós-graduação em Saúde Coletiva por unidade da Federação, Brasil, 2011}

As instituições responsáveis pela oferta dos programas de pósgraduação incluem universidades estaduais, universidades federais, uma parceria entre universidade estadual e federal e universidades privadas, das quais uma é regida pela modalidade empresarial e as demais são filantrópicas ou comunitárias. A distribuição dos programas segundo o tipo de instituição promotora está apresentada 
no Gráfico 2. Aproximadamente 62\% dos programas são oferecidos por universidades federais, $27 \%$ por universidades estaduais e o restante por instituições privadas.

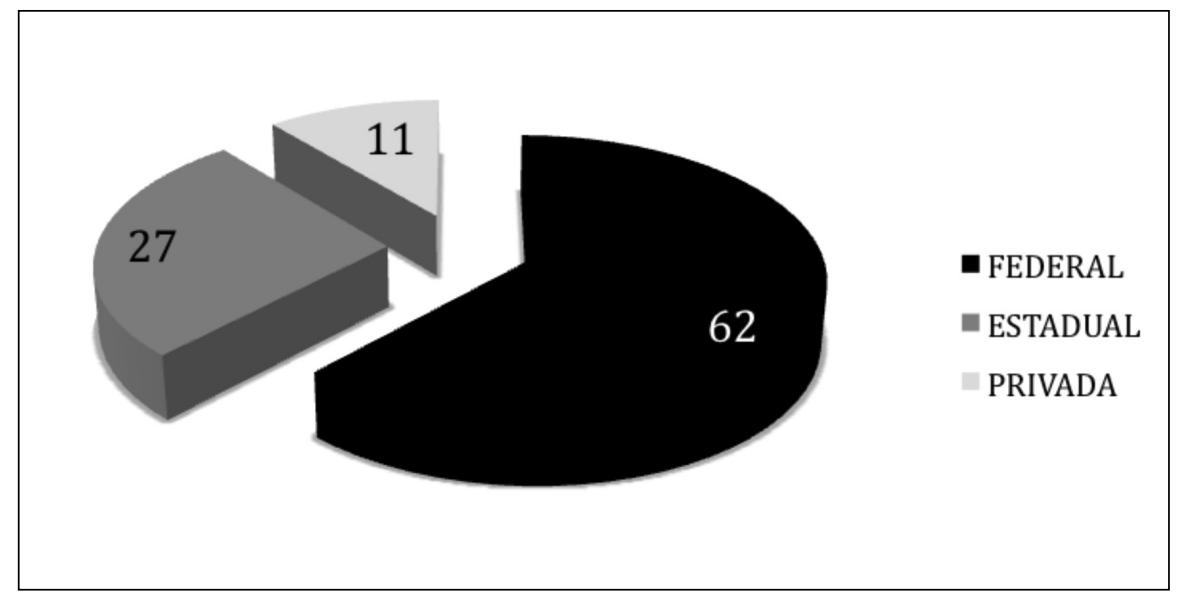

Fonte: Capes (http:/www.capes.gov.br).

\section{Gráfico 2. Distribuição dos programas de pós-graduação em Saúde} Coletiva, segundo tipo de instituição promotora, Brasil, 2011

Os programas de pós-graduação são avaliados no momento de seu credenciamento e a cada três anos. As notas variam de 1 a 7 para os programas acadêmicos e de 1 a 5 para os profissionais. As notas 1 e 2 correspondem, respectivamente, aos conceitos insuficiente e fraco, resultando no não credenciamento de cursos novos ou no descredenciamento de cursos já existentes. As notas atuais dos 54 programas ativos em Saúde Coletiva são apresentadas no Gráfico 3. Os dados mostram que aproximadamente 33\% dos programas são considerados regulares (nota 3), 35\% são classificados como bons (nota 4) e $32 \%$ são cursos muito bons ou excelentes (notas 5, 6 ou 7). 


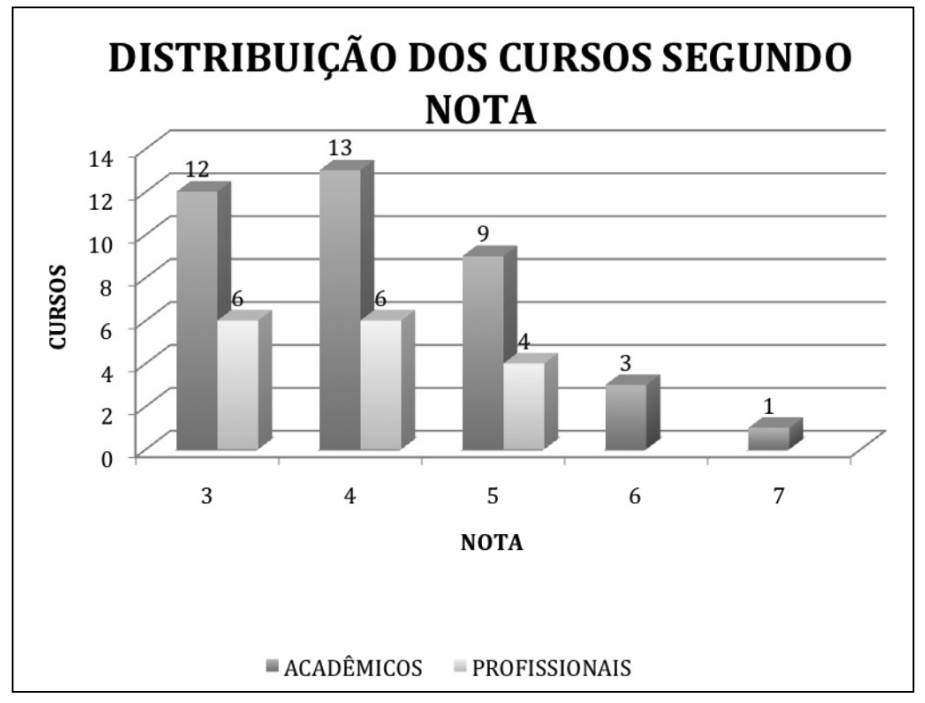

Fonte: Capes (http:/www.capes.gov.br).

Gráfico 3. Distribuição dos programas de pós-graduação em Saúde Coletiva, acadêmicos e profissionais, segundo a nota obtida na última avaliação trienal ou no credenciamento, Brasil, 2010

\section{Desafios para o futuro da pós-graduação senso estrito}

Identificam-se dois eixos principais que permitem agrupar os desafios para o desenvolvimento da Saúde Coletiva no século XXI: aqueles relacionados com os saberes e as práticas no campo, com repercussões para os programas de formação, e aquele relacionado com o ensino de pós-graduação propriamente dito.

Em relação aos desafios para o ensino de pós-graduação propriamente dito, destacam-se os seguintes aspectos:

\section{Superação das desigualdades regionais}

Idealmente, todas as unidades da Federação deveriam contar com pelo menos um programa na área de Saúde Coletiva, garantindo a formação de profissionais e pesquisadores qualificados. Em um país com dimensões continentais como o Brasil, os perfis epidemiológicos 
e as características do sistema de saúde são muito diversos, exigindo que a formação em Saúde Coletiva leve em conta as peculiaridades regionais.

Entretanto, os deslocamentos de docentes ou profissionais de saúde dos seus estados de residência para obter formação pósgraduada em outros estados ou regiões do País, além de serem difíceis e muito custosos, apresentam o risco de se mostrarem ineficazes. É bastante conhecida, em relação a outros tipos de formação, como a residência médica, a pequena taxa de retorno aos estados de origem dos profissionais que vêm buscar formação nas instituições de São Paulo e do Rio de Janeiro.

Nos cursos de pós-graduação senso estrito, o risco de que os alunos oriundos de outros estados permaneçam nos locais em que realizam sua formação pós-graduada é ainda maior pelo fato de que os alunos devem inserir-se nos grupos de pesquisa de seus orientadores, acostumando-se aos procedimentos de trabalho e beneficiando-se dos financiamentos obtidos e do convívio propriamente acadêmico que as instituições com pesquisa consolidada podem oferecer.

Grande parte das universidades brasileiras não possui docentes com formação no campo da Saúde Coletiva, o que constitui o maior empecilho para a constituição de programas de pós-graduação na área. Assim, a superação das desigualdades regionais ora observada necessitará de formas criativas de associação entre instituições com programas consolidados e instituições sem um núcleo mínimo de docentes para o desenvolvimento de um programa. Atualmente, a Capes tem entre seus programas especiais as modalidades MINTER e DINTER, respectivamente, para a formação em mestrado e doutorado. Esses programas têm por objetivo a formação e titulação de docentes das universidades, cujo corpo docente é constituído por grande número de professores sem titulação acadêmica.

O deslocamento de docentes e pesquisadores dos seus centros de trabalho para as instituições receptoras desses programas especiais se, por um lado, possibilita a formação de um maior número 
de profissionais ou docentes, por outro, não permite a esses alunos os benefícios do convívio acadêmico em um centro de excelência. Tais limitações podem ser contornadas com a previsão de estágios de curta a média duração na instituição promotora, a exemplo dos estágios sanduíche em instituições estrangeiras.

No campo da Saúde Coletiva, existem vários instrumentos que poderiam ser utilizados visando à formação de núcleos de docentes pesquisadores nas universidades e instituições de pesquisa que hoje não contam com esses recursos.

Além das associações temporárias entre instituições com programas consolidados e instituições iniciantes nesse campo, a existência de financiamento para a pesquisa em saúde, dirigido com exclusividade aos pesquisadores de cada unidade da Federação, por meio do Programa de Pesquisa para o SUS (PPSUS), realizado por parceria entre a Secretaria de Ciência Tecnologia e Insumos Estratégicos do Ministério da Saúde e as fundações de amparo à pesquisa dos estados, é um elemento chave para a fixação potencial de recémdoutores.

Incentivos a pesquisas em colaboração entre os grupos das diferentes instituições também são fundamentais para permitir a consolidação de grupos emergentes. Nesse sentido, a política científica do País tem dado prioridade, em editais específicos, para projetos oriundos de instituições localizadas nas regiões mais carentes, em associação ou não com instituições com maior tradição de pesquisa no campo.

De todo modo, a viabilização dessas diferentes estratégias de solidariedade entre programas esbarra muitas vezes no pequeno número de docentes da área de Saúde Coletiva atuando em cada uma das instituições. Apenas os programas maiores, que contam com uma relativa folga no número de docentes permanentes, podem efetivamente se engajar em atividades de formação solidária sem risco de comprometer o desempenho dos seus próprios programas. 


\section{Expansão dos programas profissionais}

Outro desafio para o desenvolvimento da pós-graduação é a expansão das atividades para outros cenários que não apenas as instituições de ensino superior. O Brasil tem parte significativa de sua produção científica no campo da Saúde Coletiva, oriunda dos programas de pós-graduação promovidos por instituições acadêmicas. Até o momento, apenas um dos programas é oferecido diretamente por serviços de saúde ou pelos órgãos coordenadores do sistema nacional de saúde.

A área da Saúde Coletiva tem que enfrentar o desafio de redefinir o caráter da maioria dos seus programas, uma vez que boa parte dos cursos apresenta perfil profissional, ainda que assim não se definam. O caráter eminentemente aplicado dos conhecimentos produzidos e das pesquisas realizadas no campo confere a essa área uma relação muito próxima com a política nacional de saúde. A maioria dos alunos de mestrado é constituída por profissionais dos serviços que buscam na formação pós-graduada um mecanismo de atualização e aprimoramento sem necessariamente pretenderem abandonar a atuação nos serviços de saúde, ingressando nas atividades acadêmicas.

Um exame dos resumos das monografias e dissertações de mestrado e em parte também das teses de doutorado é suficiente para revelar o caráter aplicado de grande parte da produção nesse campo. No entanto, como os programas profissionais não recebem apoio financeiro da Capes, necessitando da realização de convênios ou contratos entre a instituição formadora e os órgãos gestores da política de saúde para sua realização, os programas não são incentivados a rever sua concepção.

As universidades norte-americanas, por exemplo, oferecem habitualmente várias opções de titulação incluindo mestrado e doutorado em saúde pública (MPH e DPH), voltadas primordialmente para a formação de profissionais; oferecem ainda mestrado e doutorado em ciências (saúde ambiental, saúde ocupacional, epidemiologia, ciências sociais e comportamentais em saúde, entre outros) e doutorado em filosofia (PhD) em uma das disciplinas do campo. 
Esse modelo existente, por exemplo, nas escolas de saúde pública de Harvard (2010), Johns Hopkins (2010) e Berkeley (2010) poderia ser adotado pela pós-graduação brasileira, incentivando tanto a produção de novos conhecimentos nos programas acadêmicos (mestrados ou doutorados em ciências) quanto a formação de profissionais capacitados para a gestão da política nacional de saúde (mestrados e doutorados em Saúde Pública).

No presente, a maioria dos programas acadêmicos na área de Saúde Coletiva é abrangente, dedicando-se à área como um todo, sem privilegiar o recorte disciplinar. Há três programas exclusivamente em epidemiologia; portanto, com delimitação disciplinar. Os demais programas são temáticos: um programa em nutrição em Saúde Pública, um programa em saúde e meio ambiente, um programa em saúde da criança e da mulher e um programa em saúde, ambiente e trabalho. No entanto, não há diferenciação na titulação, resultando todos na concessão de títulos de mestrado ou doutorado acadêmicos.

Nos últimos anos, tem havido por parte do Ministério da Educação e da Capes forte apoio para a expansão do mestrado profissional em todas as áreas do conhecimento. A edição de portaria (MEC, 2009) regulamentando essa modalidade de formação e a abertura de editais específicos (EDITAL CAPES, 2010) devem resultar em aumento expressivo na oferta.

Recentemente, por iniciativa conjunta da Capes e da Comissão Nacional de Residência em Saúde do MEC, foi instituída uma nova modalidade de mestrado profissional associado aos programas de residência médica ou multiprofissional em saúde. 0 primeiro edital foi lançado no final de 2009. Ainda é uma incógnita o desenvolvimento dessa nova modalidade.

Portanto, nos próximos anos, a área da Saúde Coletiva deve se defrontar com a necessidade de reformular as modalidades de cursos oferecidos, buscando ampliar a oferta de titulações e o escopo temático e disciplinar dos cursos. 


\section{Excelência nacional e referência internacional}

Como em qualquer campo científico, o desafio da interlocução internacional se coloca também para a Saúde Coletiva. Entretanto, como área de pesquisa estratégica aplicada à solução de problemas relacionados diretamente com as necessidades de saúde da população e com a política nacional de saúde, à exigência de interlocução internacional adiciona-se a necessidade de excelência nacional na formação de profissionais e na produção de conhecimentos.

Os programas de pós-graduação, segundo as vocações das instituições de ensino ou pesquisa em que são oferecidos, devem almejar a excelência nacional, que, no processo de avaliação implementado pela Capes, corresponde ao alcance da nota 5; ou buscar o reconhecimento internacional (notas 6 e 7 no processo de avaliação).

A busca do reconhecimento internacional está principalmente respaldada no mérito acadêmico e se traduz na presença importante dos docentes e pesquisadores no diálogo internacional em seus campos de atuação. Esse diálogo se materializa em projetos de pesquisa conjuntos, publicação em periódicos de alto impacto, participação em corpo editorial de periódicos de impacto, posições de direção em entidades científicas internacionais, entre outros.

Mas, além dessas características relacionadas ao mérito acadêmico, a área de Saúde Coletiva valoriza o aspecto de solidariedade entre países, destacando a relevância social da atuação dos programas. O Brasil, na América Latina, é o país com maior desenvolvimento científico e maior consolidação da formação pós-graduada na área de Saúde Coletiva. Essa posição atribui ao País responsabilidades no desenvolvimento da capacidade de países vizinhos no continente sulamericano e também entre os países da Comunidade dos Países de Língua Portuguesa (CPLP) na África, Ásia e até mesmo na Península Ibérica.

Portanto, o processo de internacionalização dos programas não pode ser pensado apenas na direção da cooperação vertical, isto é, entre 
países mais desenvolvidos e o Brasil, mas também deve contemplar a cooperação horizontal com países do mesmo grau de desenvolvimento ou com menor desenvolvimento que o nosso. No cenário da globalização da educação superior em curso no mundo, a cooperação entre países é geralmente vista como sinônimo de comércio, ou seja, como relações assimétricas marcadas pelo imperialismo dos países centrais e o colonialismo dos países periféricos. Entretanto, a cooperação entre países pode e deve ser vista como sinônimo de solidariedade, isto é, relações de simetria marcadas pela busca do fortalecimento mútuo.

\section{Peculiaridade na formação em Saúde Coletiva}

Até recentemente, a área da Saúde coletiva apresentava a peculiaridade de ser uma das poucas áreas do ensino de pós-graduação para a qual não havia no País ensino de graduação. A criação dos primeiros cursos de graduação em Saúde Coletiva deu-se nos últimos anos da primeira década do século XXI e deve progressivamente alterar o panorama de formação na área.

De forma geral, a ausência de uma formação graduada anterior não havia sido sentida como um empecilho ao desenvolvimento dos cursos de pós-graduação, principalmente em sua fase inicial, caracterizada pela existência de cursos de mestrado e doutorado de longa duração nos quais as deficiências de formação anterior podiam ser supridas sem comprometer o trabalho efetivo de formação de mestres e doutores.

No entanto, com a progressiva redução da duração dos cursos para cerca de 24 meses no mestrado e 48 meses no doutorado, ficou cada vez mais evidente a carência de uma formação graduada específica, bem como da experiência anterior em iniciação científica por parte dos alunos.

Os departamentos de Saúde Coletiva, ou congêneres, nos cursos de graduação nas profissões da área da saúde, quando existem, têm frequentemente participação limitada na grade curricular e menor possibilidade de disputar as bolsas de iniciação científica existentes 
nas instituições. Essa ausência acaba resultando em carências que se refletem na condução dos programas de pós-graduação.

O caráter multidisciplinar e multiprofissional do campo torna ainda mais sentida essa carência inicial, na medida em que o corpo discente dos programas é constituído por alunos egressos dos mais diferentes cursos de graduação e com background científico bastante variado. Se, por um lado, essa diversidade enriquece a formação de todos, por outro, coloca uma série de dificuldades para a formação em um período de tempo mais curto.

A complexidade da temática da saúde tomada em sua dimensão coletiva exige uma formação centrada pelo menos em três pilares: as ciências sociais em saúde; a política, o planejamento e a gestão em saúde; e a epidemiologia (PAIM; ALMEIDA FILHO, 1998). Cada um desses campos "disciplinares" apresenta suas exigências teóricas, conceituais, metodológicas e técnicas, trazendo enorme complexidade para a formulação dos programas.

\section{Desafios para os cursos de formação pós-graduada em Saúde Coletiva: conteúdos e linhas de pesquisa}

Além dos desafios acima assinalados quanto ao conjunto dos programas de pós-graduação na área, há outra série de desafios que se colocam a cada programa em particular, no sentido de ajustar seus conteúdos e suas linhas de pesquisa às novas demandas teóricas e práticas colocadas para a área, fruto do próprio processo de transformação social e das novas necessidades da atuação na política pública de saúde.

\section{O processo de globalização e os saberes e as práticas em Saúde Pública}

Os desafios do momento atual, e que provavelmente irão se estender pelas próximas décadas do século XXI, podem ser resumidos em algumas características, tais como a rapidez de disseminação das doenças no mundo globalizado; a frequência crescente das 
crises humanitárias, provocando deslocamentos de parcelas crescentes da população em seu próprio território ou entre países; a necessidade de consolidação de estratégias locais articuladas nacional e internacionalmente; reformas setoriais comprometidas com os princípios da universalidade, integralidade e equidade no atendimento às necessidades de saúde dos indivíduos e grupos sociais; a articulação intersetorial nas políticas de promoção da saúde; o fortalecimento da capacidade regulatória do Estado na garantia da preservação da saúde; o equilíbrio entre as responsabilidades do governo; e as características do Estado democrático.

Segundo Paim e Almeida Filho (2000, p. 59, grifo nosso),

podemos entender a Saúde Coletiva como campo científico onde se produzem saberes e conhecimentos acerca do objeto saúde e onde operam distintas disciplinas que o contemplam sob vários ângulos; e como âmbito de práticas onde se realizam ações em diferentes organizações e instituições por diversos agentes dentro e fora do espaço convencionalmente reconhecido como setor saúde.

É nesse âmbito de práticas que a saúde pública redefine sua atuação como a resultante da ação coletiva tanto do Estado quanto da sociedade civil para proteger e melhorar a saúde das pessoas. Na tentativa de ajustar sua atuação às constantes transformações sociais e aos novos desafios advindos do transcurso da história, órgãos multilaterais como a Organização Mundial de Saúde e a Organização Pan-Americana da Saúde formularam, no início do século XXI, um conjunto de funções essenciais para o campo (MUÑOZ et al., 2000).

Essas funções essenciais podem constituir um guia para a formulação dos programas de formação profissional na área da Saúde Coletiva e também orientar a produção de novos conhecimentos visando o aprimoramento da atuação nesse campo. As funções essenciais incluem a análise da situação de saúde; a vigilância e o controle de riscos e danos em saúde pública; a promoção da saúde; a participação social e o fortalecimento dos cidadãos como atores do processo de tomada de decisão; o desenvolvimento de políticas, planos e capacidade de gestão que apoiem os esforços da direção nacional do 
sistema de saúde; regulação e fiscalização; avaliação e promoção do acesso equitativo aos serviços de saúde necessários; desenvolvimento e capacitação de recursos humanos; garantia da qualidade dos serviços de saúde; desenvolvimento e implementação de soluções inovadoras; redução dos impactos negativos dos desastres e das emergências em saúde pública (Ibidem).

Além das atividades e funções da saúde pública, é importante levar em conta, na formulação das propostas de formação e na definição das linhas de pesquisa que poderão nuclear as atividades dos programas de pós-graduação, os problemas mais relevantes para a saúde mundial.

Analisando as consequências negativas do processo de globalização, Buss (2006) destaca um conjunto de problemas que podem perfeitamente compor a agenda da saúde pública no início deste século XXI. O primeiro problema mencionado é a globalização da pobreza e a acentuação do processo de exclusão de parcela considerável da população dos benefícios do avanço científico obtido no século anterior. São por demais conhecidas as consequências nefastas da pobreza extrema sobre o estado de saúde, para que não seja necessário insistir nesse ponto.

O segundo ponto mencionado pelo autor é a transnacionalizacão das doenças transmissíveis, sejam elas novas doenças ou antigas doenças sob novas formas de manifestação ou ainda apresentando comportamento epidemiológico distinto do habitual. Apenas nos últimos anos, diversas crises sanitárias foram produzidas por esse processo de globalização, dentre as quais podemos destacar a epidemia da Síndrome Respiratória Aguda Grave (SARS), a pandemia de gripe A H1N1, a ameaça da gripe aviária, a expansão das microbactérias tuberculosas multirresistentes, entre outras.

Um terceiro aspecto decorre da ampliação das guerras e dos conflitos resultantes de disputas territoriais, econômicas, geopolíticas, étnicas ou motivadas por outros tipos de discriminação. Esses conflitos, além da inevitável carga de dor e violência, acabam por produzir o 
deslocamento e a migração forçada de contingentes consideráveis de pessoas que ficam expostas a todo o tipo de condições de risco para a saúde.

A globalização do tráfico de drogas e armas, além de ter expandido o consumo das drogas ilícitas, ampliou as formas de violência urbana em muitas sociedades, contribuindo duplamente para o agravamento da situação de saúde em inúmeros centros urbanos em diferentes continentes.

Finalmente, o autor destaca o aprofundamento das iniquidades sociais com reflexo tanto para o estado de saúde quanto para a organização e utilização dos sistemas nacionais de saúde. 0 aprofundamento das desigualdades sociais em saúde observado nas últimas décadas do século XX, tanto nos países desenvolvidos quanto naqueles em desenvolvimento, desencadeou o interesse crescente pelo estudo dos determinantes sociais de saúde que estavam relativamente relegados a segundo plano desde o final dos movimentos sociais contestatórios da década de 60 do século passado (BARATA, 2005).

\section{A nova saúde pública e os desafios para a pós-graduação}

Mas, diante de todas as transformações sociais com repercussões no quadro epidemiológico, o que há de novo nas práticas da saúde pública? Que implicações podem ter essas novidades na formação pós-graduada?

\section{Saúde pública nos estados democráticos}

O primeiro aspecto digno de nota no novo cenário político e institucional da maioria dos países desenvolvidos e, em parte, daqueles em desenvolvimento está relacionado aos aspectos particulares da política de saúde nos estados democráticos. As políticas públicas nos ambientes democráticos são concebidas como resultantes de contratos sociais entre um Estado estratégico e cidadãos ativos que, longe de aceitarem medidas impositivas, passam a atuar ativamente na definição das necessidades coletivas de saúde, bem como na 
escolha das alternativas de respostas sociais aos problemas coletivos. Diferentemente da tradição da velha saúde pública, na qual a burocracia estatal constituída por técnicos e especialistas decidia quais eram os problemas e como enfrentá-los, necessitando apenas da anuência das autoridades políticas para implementar as soluções a esses problemas، nos estados democráticos, cada vez mais, a sociedade civil organizada se apresenta como ator qualificado na cena política, reivindicando participação ativa na formulação dos problemas e de suas soluções. 0 protagonismo na formulação e implementação das políticas de saúde se desloca do lócus exclusivo do governo para a esfera dos movimentos políticos na sociedade, aí incluídos os trabalhadores e profissionais de saúde e as organizações sociais de potenciais usuários e beneficiários dessas políticas.

Kurland (2002) afirma que tanto a saúde pública quanto a democracia florescem quando as informações são amplamente disseminadas e compreendidas, quando os benefícios e os custos são debatidos, quando as decisões são compartilhadas por aqueles que serão afetados pelas políticas e quando o interesse público é visto como mais valioso que o ganho privado.

\section{Direito à saúde como direito humano fundamental}

Outra novidade importante no processo de desenvolvimento da saúde pública no século XXI é a consagração do direito à saúde como um dos direitos humanos fundamentais. Esse direito aparece nas diferentes constituições nacionais como uma responsabilidade do governo na promoção e defesa da saúde populacional. O direito sanitário, nesse marco político democrático, busca o equilíbrio entre os poderes legais e as obrigações do Estado na proteção coletiva da saúde e uma limitação do poder desse mesmo Estado face à necessidade de garantir direitos individuais. Nem sempre esse equilíbrio tem sido alcançado de maneira satisfatória, resultando em intervenção do Poder Judiciário nas políticas do Executivo, visando o estabelecimento da justiça, muitas vezes, porém, com resultados que ficam muito distantes da intenção original (CHIEFFl; BARATA, 2009). A defesa dos direitos individuais ocupa posição central na tradição do direito 
brasileiro, havendo pouco ou nenhum espaço para uma doutrina social que subordine os interesses individuais ao bem público, o que torna ainda mais difícil a garantia ao direito à saúde na perspectiva coletiva.

\section{Papel regulatório do Estado}

Um tema fundamental na nova saúde pública é o papel regulatório do Estado. A questão da regulação envolve a demonstração da existência do risco, a comprovação da efetividade das medidas regulatórias, análises de custo-efetividade das intervenções, opção entre alternativas de ação menos restritivas e distribuição equitativa dos direitos e deveres. Há duas áreas de conflito inerentes ao exercício da regulação no campo da saúde pública: de um lado, o conflito entre interesse individual e interesse coletivo e, de outro, o conflito entre a defesa do bem público face ao interesse das corporações.

Kurland (2002) aponta os principais obstáculos que a saúde pública enfrenta no exercício de sua função regulatória. Dentre eles, a autora destaca a visão estreita do que é considerado evidência científica. Os opositores do uso do princípio da precaução desconsideram os conhecimentos produzidos pela epidemiologia na demonstração das relações de associação entre exposições e desfechos negativos em saúde, alegando que apenas a ciência biomédica é capaz de produzir evidências científicas satisfatórias. Talvez os casos mais notórios desse tipo de alegação tenham sido a negativa em considerar o tabagismo como o principal fator de risco para o câncer de pulmão e o uso do teste para hepatite $B$ na triagem de doadores de sangue no início da epidemia da AIDS.

Outro obstáculo poderoso é a informação disponível para a sociedade sobre os benefícios da decisão de agir ou não agir. O controle sobre a informação, a condução de investigações, o apoio a pesquisas enviesadas e a sonegação das informações negativas por parte das corporações tornam impossível para a sociedade civil realizar uma análise independente e informada.

A ação em face à incerteza é talvez o aspecto mais vulnerável da prática regulatória. O reconhecimento de que muitas vezes não há, 
e provavelmente nem haverá, no futuro próximo, evidências científicas e certezas que embasem a ação torna a tomada de decisão mais complexa. Nessas situações, só a ponderação lógica entre benefícios e malefícios relacionados à ação e em contrapartida à inação pode auxiliar a autoridade sanitária (VILLALBí et a.I, 2007).

Finalmente, parte das fragilidades no processo de regulação tem a ver com a iniquüidade na distribuição dos aspectos negativos de certas práticas corporativas. Segundo Kurland (2002), parte-se do princípio de que as indústrias têm o direito de produzir o que queiram; de que os produtos são considerados seguros até que se prove o contrario; que o direito ao lucro sobrepõe-se ao direito da sociedade defender sua saúde; e que os profissionais de saúde pública defendem interesses estreitos, enquanto as corporações representam os interesses públicos mais amplos. Para a autora, essa manobra de encobrimento ideológico só é possível porque os grupos mais prejudicados são constituídos predominantemente por pobres, trabalhadores, negros ou população de outros países.

\section{Exclusão social}

Outro aspecto que distingue a saúde coletiva da prática tradicional da saúde pública é a consideração da exclusão social como um dos fenômenos sociais centrais na sociedade contemporânea. Diferentemente dos processos sociais que marcaram a segunda metade do século XIX e a primeira metade do século XX, caracterizados fundamentalmente pelo enfrentamento entre classes sociais, o aprofundamento do capitalismo na sua vertente financeira aliado à rápida transformação nos processos produtivos produziu a exclusão de parcela considerável da população mundial do mercado de trabalho e do consumo de bens materiais e não materiais, gerando novas formas de marginalização no processo de reprodução social. As diferentes formas de exclusão social estão todas elas associadas à deterioração do estado de saúde. O enfrentamento da exclusão social implica tanto a produção de conhecimentos sobre o processo e seus desdobramentos quanto a adoção de políticas de combate à pobreza e de redução dos efeitos nocivos decorrentes do racismo, sexismo e de outras formas de discriminação. 


\section{5. Âmbito de práticas e formas de atuação}

Outra novidade no campo de práticas da saúde pública é a ampliação do âmbito e das formas de atuação. A prestação de serviços de saúde se faz atualmente por meio de serviços públicos, fundações, empresas e organizações sociais, expandindo o âmbito e as formas de gestão. A presença crescente das corporações nas agências multilaterais e nos organismos nacionais gestores da política de saúde também é um dado novo que modifica formas de atuação e requer maior vigilância pela sociedade.

Finalmente, a percepção do setor saúde como um dos setores econômicos mais dinâmicos das sociedades ocidentais, seja pela criação de empregos formais, seja pela realização do capital das indústrias do complexo produtivo da saúde, deslocou o eixo e o protagonismo política da OMS para entidades do setor financeiro, como o Banco Mundial e o Banco Interamericano de Desenvolvimento, que passaram a ser as entidades mais influentes na determinação dos rumos da política de saúde em âmbito mundial.

\section{Repercussões para a formação}

Todas essas transformações exigem do setor formativo um reposicionamento tanto no que se refere à formação acadêmica quanto ao que se refere à formação profissional. Fee (2008), analisando as transformações nas escolas de saúde pública norte-americanas, aponta o fortalecimento da pesquisa científica como uma das causas para o divórcio entre teoria e prática no campo. Segundo a autora, a existência de financiamento próprio para a atividade de pesquisa acabou por hipertrofiar nas universidades a produção de conhecimentos científicos à custa de menor atenção para as atividades de formação profissional, produzindo progressivo afastamento das escolas de saúde pública dos órgãos responsáveis pela política de saúde, com evidente prejuízo para a formação.

Daí a necessidade de considerar pelo menos dois grandes campos de formação: um campo acadêmico, compreendendo a pós- 
graduação senso estrito, especialmente os programas de doutorado, e um campo prático, compreendendo o ensino de graduação, a pósgraduação lato senso (especialização e residência) e a pós-graduação senso estrito (mestrado e doutorado profissionais).

As características desejadas para a formação acadêmica devem ter em conta a necessidade de formar pesquisadores: capazes de identificar problemas de pesquisa coerentes com as necessidades de saúde; com sólida formação teórica e metodológica; capazes de interagir com pesquisadores de outros campos disciplinares na construção de abordagens transdisciplinares; com correição ética; capazes de captar os recursos necessários para sua linha de pesquisa; capazes de manter regularidade de publicações; capazes de liderar a condução de grupos de pesquisa; que tenham comunicação social com políticos, patrocinadores e com a comunidade; e capazes de reproduzir o processo de trabalho na ciência por meio da formação de novos pesquisadores.

Já os profissionais de saúde pública devem ter capacidade técnica para identificar e hierarquizar as necessidades sociais em saúde; organizar saberes e instrumentos técnicos na configuração de modelos tecnológicos de intervenção para o enfrentamento dos problemas de saúde; avaliar o impacto das intervenções realizadas; ter capacidade de negociação para o exercício da prática intersetorial; ter capacidade de intermediação e de tradução do conhecimento acadêmico para a prática em serviços (pesquisa translacional); e ter a capacidade de fornecer evidências cientificamente embasadas para auxiliar a tarefa regulatória do Estado.

Claramente, todas essas competências não se esgotam em um único momento formativo, sendo a resultante de todo um processo de formação composto por diferentes etapas. De todo modo, cabe aos formuladores, proponentes e executores dessas etapas repensar seus modelos em função dos vários aspectos aqui tratados. Só assim poderemos ser capazes de atender ao apelo do nosso presidente da Federação Mundial de Associações de Saúde Pública, Paulo Buss (2006, p. 295), quem exortou os sanitaristas a 
lutarem contra a globalização injusta, a pobreza e a exclusão, contra a corrida armamentista e a violência, por um meio ambiente sustentável, pela equidade em saúde, pela paz e a solidariedade entre todos os povos do mundo, para que alcancemos melhores condições de saúde e qualidade de vida, não no futuro distante mas hoje, aqui e agora.

Recebido 01/11/2011

Aprovado 09/07/2012

\section{Referências bibliográficas}

BARATA, R. B. Tendências no ensino da epidemiologia no Brasil. Revista Panamericana de Salud Pública, v. 2, n. 5, p. 334-341,1997.

Epidemiologia social. Revista Brasileira de Epidemiologia, v. 8, n. 1, p. 7-17, 2005.

BERKELEY - School of Public Health, University of California, Berkeley. Academic Programs. 2010. Disponivel em: http://sph.berkeley.edu. Acesso em: 20 abr. 2010.

BUSS, P. M. Globalización, pobreza y salud. Premio Conferencia Hugh Rodman Leavell. Salud Colectiva, v. 2, n. 3, p. 281-297, 2006.

CAPES - Coordenação de Aperfeiçoamento de Pessoal de Nivel Superior. Cursos recomendados. Cadernos de Indicadores dos Programas. 2010. Disponivel em: http:/www.capes.gov.br. Acesso em: 19 abr. 2010.

CHIEFFI, A. L.; BARATA, R. B. Judicialização da política pública de assistência farmacêutica e eqüidade. Cadernos de Saúde Pública, v. 25, n. 8, p. 1839-1849, 2009.

EDITAL CAPES. Edital $n^{\circ}$ 5/2010/Capes/DAV. Chamada de novas propostas de cursos de Mestrado Profissional. Disponivel em: http:/ www.capes.gov.br. Acesso em: 03 out. 2011.

FEE, E. Divórcio entre teoria e prática: o sistema de treinamento em saúde pública nos Estados Unidos. Ciência \& Saúde Coletiva, v. 13, n. 3, p. 841-851, 2008. 
HARVARD - Harvard School of Public Health. Departments/Programs. 2010. Disponivel em: http:/ hsph.harvard.edu. Acesso em: 20 abr. 2010.

HOPKINS - Johns Hopkins Bloomberg School of Public Health. Academics. 2010. Disponivel em: http:/ www.jhsph.edu. Acesso em: 20 abr. 2010.

KURLAND, J. The heart of the precautionary principle in democracy. Public Health Report, v. 117, p. 498-500, 2002.

LEAL, M. C.; FREITAS, C. M. (Orgs). Cenários possiveis: experiências e desafios do mestrado profissional na saúde coletiva. Rio de Janeiro: Editora Fiocruz, 2006.

MEC - Ministério da Educação. Portaria Normativa $\mathrm{n}^{\circ} 17$ de

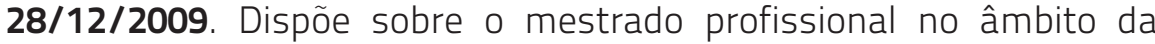
Fundação Coordenação de Aperfeiçoamento de Pessoal do Ensino Superior - CAPES. Diário Oficial [da] República Federativa do Brasil, Poder Executivo, Brasília, DF, 29 dez. 2009. n 248.

MUÑOZ, F.; LÓPEZ-ACUNÃ, D.; HALVERSON, P.; MACEDO, C. G.; HANNA, W.; LARRIEU, M.; UBILLA, S.; ZEBALLOS, J. L. Las funciones esenciales de la salud pública: un tema emergente en las reformas del sector de la salud. Revista Panamericana de Salud Pública, v. 8, n. 1/2, p. 126-134, 2000.

PAIM, J. S.; ALMEIDA FILHO, N. Saúde coletiva: uma "nova saúde pública" ou campo aberto a novos paradigmas? Revista de Saúde Pública, v. 32, n. 4, p. 299-316, 1998.

A crise da saúde pública e a utopia da saúde coletiva. Salvador: Casa da Qualidade Editora, 2000.

VILLALBİ, J. R.; CUSİ, M.; CAYLÀ, J. A.; DURÀN, J.; GUIX, J. El ejercicio de la autoridad sanitaria: los principios, lo reglamentado y la incertidumbre.

Gaceta Sanitaria, v. 21, n. 2, p. 172-175, 2007. 